\title{
Referral for abortion
}

\author{
PRATHIMA RADHAKRISHNAN
}

Consultant, Bangalore Fetal Medicine Centre ,10 C J D'Souza Road, Bangalore 560025 INDIA email: prathimabfmc@hotmail.com

\section{Chervenak FA, McCullough LB. The ethics of direct and indirect referral for termination of pregnancy. Am J Obstet Gynecol 2008;199:232.e1-232.e3}

Referral of patients for termination of a pregnancy by those physicians who are against abortion always raises ethical issues. The authors in this paper refer to the Committee on Ethics Opinion from the American College of Obstetricians and Gynecologists (ACOG), "The limits of conscientious refusal in reproductive medicine," which stated that physicians opposed in conscience to abortion nonetheless have an ethical obligation to "provide accurate and unbiased information" and to "refer patients in a timely manner to other providers." (1) The American Association of Pro-Life Obstetricians and Gynecologists in their response to this opinion states:"The idea that physicians are obligated to provide or refer for elective abortion services simply on the basis of 'patient request' is antithetical to the practice of modern medicine." (2)

The authors have discussed the ethical considerations for physicians who are morally opposed to termination of pregnancy. They analyse the various types of referrals, ie, "direct" and "indirect" and identify implications of each. They suggest that there are two ethical indications for referral, namely, beneficence-based and autonomy-based indications. Beneficence is the ethical principle that takes an evidencebased, clinical perspective on the patient's health-related and other interests and creates an obligation to act in such a way as to result in the greater balance of clinical benefits over clinical harms for the patient (3). Beneficence requires direct referral of patients for medically-indicated intervention. Respect for autonomy is the ethical principle that takes the patient's perspective on the patient's health-related and other interests and creates the obligation to empower the patient's autonomy in the informed consent process (3). Respect for autonomy requires only indirect referral of patients for intervention that has only autonomy-based indications.

Direct referral is achieved by communicating to the referral physician directly and transfer of patient care. This allows for prompt treatment and the referring physician is obliged to ensure that the patient receives appropriate and prompt care.

Indirect referral is based on patient autonomy as the referring physician provides the patient with information regarding institutions that would perform such a procedure and the patient chooses the place of treatment. When it comes to termination of a pregnancy there are many more issues like the pregnant woman's cultural, familial, religious, and personal beliefs. It is not always possible for physicians to understand this fully. Respect for autonomy requires every physician to acknowledge and respect such values and beliefs and not discriminate against patients based on differences of these values and beliefs with those of the physician.

It is the physician's responsibility to empower the exercise of autonomy by the patient, by giving the patient referral information, without taking any additional steps to ensure the referral actually occurs. However as the indications for referral are exclusively autonomy-based, direct referral is not ethically obligatory but is permissible, the authors argue. Unfortunately sepsis from illegally performed abortions is not history yet; in India it is even more rampant. It is also the referring physician's responsibility to protect the patient from loss of future fertility, health, or even her life. It is impossible for a physician to know all the physicians or non-physicians who incompetently perform abortions. However, it is realistic to expect a physician to know that there are healthcare organisations in which the physician can have confidence that an abortion, should it be elected by the pregnant woman, would be done competently and safely.

By exercising her autonomy in an "indirect referral" system, the referring physician is not a party to the termination process, opine the authors. Whereas in a "direct referral" system, the physician is indeed a direct party to the referral and the performance of the procedure.

The authors conclude that "when referral is autonomy based, only indirect referral, providing referral information but not ensuring that referral occurs, should be the clinical ethical standard of care. Direct referral is a matter of individual physician discretion, not the clinical ethical standard of care".

Termination of a pregnancy is indeed a contentious issue which arouses discussions and debates in the medical and the nonmedical fraternity. For parents who are carrying an anomalous foetus, it is almost always an emotional turmoil, often leading to conflicts between their personal and religious beliefs. In India, in addition, there are huge financial, social and emotional implications, particularly when a baby with an anomaly is born. The parents have to get the baby treated, many times requiring expensive surgical interventions and costly medications, not to mention the neonatal intensive care. Some of these will need 
to continue under medical supervision and medications for a long time. Due to financial constraints some parents will either not initiate treatment at all or discontinue treatment midway. Upon the diagnosis of a foetal anomaly, parents who anticipate that they are incapable of making this financial commitment will opt to terminate the pregnancy, many times much against their emotional wishes.

According to the Consortium on National Consensus for Medical Abortion in India, every year an average of about 11 million abortions take place annually and around 20,000 women die every year due to abortion-related complications (4). Most abortion- related maternal deaths are attributable to illegal abortions (5). The Medical Termination of Pregnancy (MTP) Act of India clearly states the conditions under which a pregnancy can be ended or aborted, the persons who are qualified to conduct the abortion and the place of implementation.

In India, the majority of patients will choose their doctor and decide who is going to take care of their pregnancy. In some parts, a general practitioner will refer the patient to the obstetrician in the locality, particularly if there is any complication in the pregnancy. The onus of ensuring that the location of the termination is legalised by the MTP Act of India is on the obstetrician or the institution conducting the termination. There are obstetricians opposed to the termination of a healthy but "unwanted" pregnancy because of their personal and religious beliefs. In these situations, the commonest referral pattern would be to a colleague who is known to the obstetrician rather than the patient choosing one. The authors in this article refer to this as "direct referral." In most situations, the referring obstetrician is aware of the colleague's practices and the intention to a safe treatment is met with However, in the presence of an anomalous foetus, if the parents want to discontinue the pregnancy, most obstetricians will oblige. If however, they anticipate any maternal complications, then the parents are referred to tertiary institutions.

Termination of a pregnancy, in India, is allowed only before 20 weeks' gestation by The Medical Termination (MTP) Act of India, irrespective of the lethality of the foetal abnormality. The only exception would be if the mother's condition is life threatening in which case it can be argued that the termination is undertaken to save the mother's life. In the United Kingdom, there is no upper limit for the gestation at which a pregnancy can be terminated based upon "substantial risk of serious physical or a mental handicap" for the child. However, "serious handicap" is not defined in the Act and there is no numerical definition of "substantial risk" (6).

Due to the extreme variations in the practice of foetal ultrasound and detection of foetal abnormalities, it is very difficult to uniformly implement one law based on the "ethics" of one group of people for the entire country. A law similar to the one in the UK, in India, would cause more confusion as "lethality" and "seriousness of the handicap" can be open to any number of interpretations. Thirdly, it would be a Herculean task to suggest a uniform pattern of referral based on beneficence or autonomy.
The authors have suggested that "direct referral" is beneficencebased and "indirect referral" is autonomy-based. They opine that "direct referral for termination of pregnancy is not ethically required but is permissible". In India, the practice of medicine is very variable. In the majority of cases, particularly for the termination of an "unwanted" pregnancy, the woman will choose her gynaecologist who in most situations will not be morally opposed to terminating the pregnancy. Those who are opposed refer to their colleagues in most situations to complete the process of the termination. This is a widely well accepted practice, ie, "direct referral" is the most common practice.

In the presence of a foetal abnormality, most parents will seek a further expert opinion, many times from another gynaecologist. In the majority of the situations the patient decides who she is going to have the termination from, either depending upon her comfort level with the gynaecologist or the proximity of the hospital to her home. Hence, patient autonomy is exercised in these cases.

In many western countries, there are powerful anti-abortion lobbies. In India, there are small anti-abortion groups scattered but none of them have made their presence felt on a national level. In western society the "ethics" of abortion play a huge role, so much so that objections are raised for "direct referrals". In India, the situation is different, also because financial status and the need for expensive medical treatment play a huge role in parents deciding whether to terminate the pregnancy and if so where and with whom.

In India, there are both types of referral, each having its own merits. To consider one ethical and the other not would not be right due to the huge variation in medical practice.

\section{References}

1. American College of Obstetricians and Gynecologists. ACOG Committee Opinion No. 385 November 2007: the limits of conscientious refusal in reproductive medicine. Obstet Gynecol.2007 Nov;110(5):1203-8.Cited in PubMed; PMID 17978145.

2. DeCook JL. Response to the ACOG Ethics Committee Opinion \# 385. In: Issues in depth- ethical commentaries [Internet]. River Ave (Holland): American Association of Pro-Life Obstetricians and Gynecologists; 2008 Feb 6 [cited 2009 Sep1]. [about 5 screens]. Available from: http://www. consciencelaws.org/Examining-Conscience-Ethical/Ethical79c.htm

3. McCullough LB, Chervenak FA. Ethics in obstetrics and gynecology. New York: Oxford University Press; 1994.300p.

4. Mittal S. Introduction on Consortium on National Consensus for Medical Abortion in India [Internet]. New Delhi: Consortium on National Consensus for Medical Abortion in India; [cited 2009 Sep 1]. [about 2 screens]. Available from: http://www.aiims.ac.in/aiims/events/ Gynaewebsite/ma_finalsite/introduction.html

5. lyengar S. Current status of abortion in India [Internet]. New Delhi: Consortium on National Consensus for Medical Abortion in India; [cited 2009 Sep 1]. [about 3 screens]. Available from: http://www.aiims.ac.in/ aiims/events/Gynaewebsite/ma_finalsite/report/1_1_1.htm

6. Lilford RJ, Thornton J. Ethics and late termination of pregnancy. Lancet.1993 Aug 21;342(8869):499. Cited in PubMed; PMID 8102456 